\title{
Even lobar deposition of poorly soluble gold nanoparticles (AuNPs) is similar to that of soluble silver nanoparticles (AgNPs)
}

\author{
Hoi Pin Kim², Jin Kwon Kim², Mi Seong Jo', Jung Duck Park ${ }^{3}$, Kangho Ahn², Mary Gulumiann ${ }^{4,5,6}$,
} Günter Oberdörster ${ }^{7 *}$ and $\|$ Je $Y u^{1,8^{*}}$ (D)

\begin{abstract}
Background: Information on particle deposition, retention, and clearance is important when evaluating the risk of inhaled nanomaterials to human health. The revised Organization Economic Cooperation and Development (OECD) inhalation toxicity test guidelines now require lung burden measurements of nanomaterials after rodent subacute and sub-chronic inhalation exposure (OECD 412, OECD 413) to inform on lung clearance behavior and translocation after exposure and during post-exposure observation (PEO). Lung burden measurements are particularly relevant when the testing chemical is a solid poorly soluble nanomaterial. Previously, the current authors showed that total retained lung burden of inhaled soluble silver nanoparticles (AgNPs) could be effectively measured using any individual lung lobe.
\end{abstract}

Methods and results: Accordingly, the current study investigated the evenness of deposition/retention of poorly soluble gold nanoparticles (AuNPs) after 1 and 5 days of inhalation exposure. Rats were exposed nose-only for 1 or 5 days $(6 \mathrm{~h} /$ day) to an aerosol of $11 \mathrm{~nm}$ well-dispersed AuNPs. Thereafter, the five lung lobes were separated and the gold concentrations measured using an inductively coupled plasma-mass spectrophotometer (ICP-MS). The results showed no statistically significant difference in the AuNP deposition/retention among the different lung lobes in terms of the gold mass per gram of lung tissue.

Conclusions: Thus, it would seem that any rat lung lobe can be used for the lung burden analysis after short or long-term NP inhalation, while the other lobes can be used for collecting and analyzing the bronchoalveolar lavage fluid (BALF) and for the histopathological analysis. Therefore, combining the lung burden measurement, histopathological tissue preparation, and BALF assay from one rat can minimize the number of animals used and maximize the number of endpoints measured.

Keywords: Gold nanoparticles, Lung lobar deposition, Lung retention, Poorly soluble particles, Silver nanoparticles

\footnotetext{
* Correspondence: Gunter_Oberdorster@URMC.Rochester.edu;

u1670916@chollian.net

${ }^{7}$ Department of Environmental Medicine, University of Rochester, Rochester,

NY, USA

${ }^{1}$ Aerosol Toxicology Research Center, HCTm CO.,LTD, Icheon, South Korea

Full list of author information is available at the end of the article
}

(c) The Author(s). 2020 Open Access This article is licensed under a Creative Commons Attribution 4.0 International License, which permits use, sharing, adaptation, distribution and reproduction in any medium or format, as long as you give appropriate credit to the original author(s) and the source, provide a link to the Creative Commons licence, and indicate if changes were made. The images or other third party material in this article are included in the article's Creative Commons licence, unless indicated otherwise in a credit line to the material. If material is not included in the article's Creative Commons licence and your intended use is not permitted by statutory regulation or exceeds the permitted use, you will need to obtain permission directly from the copyright holder. To view a copy of this licence, visit http://creativecommons.org/licenses/by/4.0/. The Creative Commons Public Domain Dedication waiver (http://creativecommons.org/publicdomain/zero/1.0/) applies to the data made available in this article, unless otherwise stated in a credit line to the data. 


\section{Background}

OECD inhalation test guidelines have recently been revised to cover testing of nanoparticles, including toxicokinetic studies and lung burden measurements. For inhalation exposure, the first step of a toxicokinetic study is explained in revised inhalation toxicity guidelines 412 (subacute) and 413 (subchronic) [1, 2]. When the inhaled test nanomaterials are poorly soluble, OECD guidelines mandate that the lung burden should be measured to inform about the pulmonary-retained dose. Such lung burden measurements should be performed for all test chemicals within $24 \mathrm{~h}$ after exposure termination and at two or more additional post-exposure observation (PEO) intervals $[1,2]$. However, the inclusion of two additional lung burden analyses for two additional post-exposure observation periods means an increased use of animals, from 40 to 120 animals for OECD 412 [1] and from 80 to 160 animals for OECD 413 [2]. In a previous report, we evaluated the variability of nanoparticle deposition in specific lung lobes of rats following inhalation exposure to soluble silver nanoparticles (AgNP, $20 \mathrm{~nm}$ ). The results showed that $20 \mathrm{~nm}$ inhaled well-dispersed AgNPs were evenly deposited and retained in all lung lobes in terms of the Ag mass per gram of lung tissue [3]. Therefore, this suggests that any lung lobe can be used to determine the total lung burden, as long as the same lobe is sampled for these measurements. The remaining lung lobes can then be used for bronchoalveolar lavage fluid (BALF) collection and histopathological analysis, provided proper occlusion of the lung lobe is performed for the lung burden measurement. However, the results also indicated the need for further studies to determine the evenness of lobar retention in the case of poorly soluble nanoparticles. Accordingly, this report analyzes the particle deposition and retention in each lung lobe of a rat model to identify a representative lobe for lung burden measurements. Gold nanoparticles (AuNPs) with an average diameter of 11 nm were generated, as approximately $20-25 \%$ of inhaled particles of this size range are known to be deposited efficiently in the alveolar region with the Multiple-Path Particle Dosimetry Model (MPPD) and International Commission on Radiological Protection (ICRP) lung deposition models [4-6]. After 1 and 5 days of AuNP inhalation exposure, the rats were sacrificed and the lung lobes separated for lung burden analysis. The amounts retained in the lung lobes were then evaluated in terms of mass and particle number.

\section{Materials and methods}

\section{Gold nanoparticle generation}

The AuNPs used in this study were generated based on a well-established evaporation/condensation generation method, as previously described [3, 7-9] The generator consisted of a small ceramic heater connected to an AC power $(112-113 \mathrm{~V})$ supply and was housed within a quartz tube case $(70 \mathrm{~mm}$ in diameter and $140 \mathrm{~mm}$ long). The heater dimensions were $50 \times 5 \times 1.5 \mathrm{~mm}$, and a surface temperature of about $1500{ }^{\circ} \mathrm{C}$ within a local heating area of $5 \times 10 \mathrm{~mm}^{2}$ was achieved within about $10 \mathrm{~s}$. Approximately $80 \mathrm{mg}$ of the source material gold wire (purity $99.99 \%$; $0.5 \mathrm{~mm}$ diameter, density $19.35 \mathrm{~g} / \mathrm{cm}^{3}$, Higgslab Co., Ltd., South Korea) was positioned at the highest temperature point. The rats were exposed to the AuNP aerosol in a nose-only exposure chamber (30 ports, flow past, HCT, Icheon, Korea); 20 ports for animal exposure and 5 ports for chamber monitoring, including particle monitoring using a real-time particle monitor, sampling, and chamber environmental monitoring. Clean (dry and filtered) air was used as the carrier gas, and the gas flow was maintained at $25.0 \mathrm{~L} / \mathrm{min}$ ( $\mathrm{Re}=572$, laminar flow regime) using a mass flow controller (MFC, AERA, FC-7810CD-4 V, Japan) [10]. In the current study, the exposure system consisted of two chambers: AuNP exposure and fresh air control. The generator used $3 \pm 0.1$ LPM (liters per minute) for generating the aerosol and $22 \pm 1$ LPM for the aerosol dilution system. The total air flow volume in each chamber was 25 LPM and controlled by a mass flow controller (MFC, AERA, FC-7810CD-4 V, Japan). The flow rate to each port in the nose-only chamber was approximately 1 LPM, similar to the $0.75 \mathrm{~L} / \mathrm{min}$ flow recommended by Pauluhn [11].

\section{Monitoring of inhalation chamber and analysis of AuNPs}

The nanoparticle size distribution was measured in each chamber directly in real-time using a differential mobility analyzing system (DMAS); combining a differential mobility analyzer (DMA-20, 4220, range 6-225 nm, HCT Co., Ltd. Korea) and condensation particle counter (CPC, 3775, size range $4 \mathrm{~nm}-3 \mu \mathrm{m}$, TSI INC., Shoreview, MN). Nanoparticles from 6 to $225 \mathrm{~nm}$ were measured using sheath air at $15 \mathrm{~L} / \mathrm{min}$ and polydispersed aerosol air at $1.5 \mathrm{~L} / \mathrm{min}$ for the DMAS and CPC, respectively. In addition, the mass concentration of AuNPs was determined chemically using an atomic absorption spectrophotometer (AAS, Perkin-Elmer $900 \mathrm{~T}$, Waltham, MA, USA) after sampling on a mixed cellulose ester (MCE) filter (size: $37 \mathrm{~mm}$ and pore size $0.45 \mu \mathrm{m}, \mathrm{SKC}, \mathrm{UK}$ ) at a flow rate of $1.0 \mathrm{~L} / \mathrm{min}$ [11]. Three samples were taken from the ports of the inhalation chamber each day during the 5-day exposure. The target mass concentration of generated AuNPs in the chambers was $40 \mu \mathrm{g} / \mathrm{m}^{3}$.

\section{Transmission Electron microscopy (TEM)}

The TEM samples were collected on a TEM grid (200 mesh, Veco, Eerbeek, Holland) for 3 min using a nanocollector (HCT Co., Ltd., Icheon, Korea) in each 
chamber during the exposure period, and visualized under TEM (JEM-2100F, JEOL, Japan). The diameters of 200 randomly selected particles were measured at a magnification of 100,000, and the AuNPs analyzed using an energy-dispersive $\mathrm{x}$-ray analyzer (EDX, Oxford. UK) at an accelerating voltage of $75 \mathrm{kV}$.

\section{Animals and exposure}

Six-week-old male (20 rats; $213.64 \pm 1.31$ of weight (g); mean \pm S.E), specific-pathogen-free (SPF) SpragueDawley rats were purchased from Orient Bio (Seongnam, Korea) and acclimated for 2 weeks before starting the experiments. During the acclimation and experiment periods, the rats were housed in polycarbonate cages ( 5 rats per cage) in a room with controlled temperature $\left(21.1 \pm 0.33^{\circ} \mathrm{C}\right)$ and humidity $(48.8 \pm 4.1 \%)$ with a 12 -h light/dark cycle. The rats were fed a rodent diet (Woojung E\&C, Seoul, Korea) and filtered water ad libitum. The rats were adapted to the nose-only tubes for a week with daily tube placement for $2 \mathrm{~h}$. The 8 -week-old rats, weighing $331.2 \pm 2.8 \mathrm{~g}$ (20 rats mean $\pm \mathrm{SE}$ ), were then divided into 4 groups: fresh air control for 1 day (5 rats, $331.4 \pm 5.5 \mathrm{~g}$ ) and 5 days ( 5 rats; $331.8 \pm 6.3 \mathrm{~g}$ ), and AuNP exposed $(6 \mathrm{~h} /$ day) for 1 day ( 5 rats, $331.3 \pm 7.1 \mathrm{~g}$ ) and 5 days ( 5 rats, $330.2 \pm 5.4 \mathrm{~g}$ ). The exposure concentration selected was a concentration that maximally generated from the generator and also based on our previous AuNP (13 nm) 5-day repeated inhalation exposure and AuNP $(5 \mathrm{~nm})$ 90-day repeated inhalation exposure studies $[8,12]$. In the 5-day AuNP $(13 \mathrm{~nm})$ inhalation study at $13 \mu \mathrm{g} / \mathrm{m}^{3}$ did not show any noticeable inflammation and 90-day AuNP (5 nm) inhalation study at 0.04 to $20 \mu \mathrm{g} / \mathrm{m}^{3}$ showed minimal alveoli, an inflammatory infiltrate with a mixed cell type, and increased macrophages in the high-dose rats. Thus, our study concentration $35 \mu \mathrm{g} / \mathrm{m}^{3}$ for short-term exposure may not induce significant lung inflammation and result in sufficient tissue $\mathrm{Au}$ concentration by ICP-MS analysis. Therefore, histopathological evaluation and bronchoalveolar lavage fluid analysis that may exert particle deposition to the lung lobes were not conducted. The animals were examined daily on weekdays for any evidence of exposure-related effects, including respiratory, dermal, behavioral, nasal, or genitourinary changes suggestive of irritation. The body weights were evaluated at the time of purchase, at the time of grouping, once a week during the inhalation exposure, and before necropsy (results are not shown). The rat experiment was approved by the Hanyang University Institutional Animal Care and Use Committee in South Korea (HY-IACUC-2019-0049).

\section{Lung burden measurement}

After 1 (6-h) or 5 days of exposure, the animals were immediately sacrificed by anesthetizing via an intraperitoneal injection of pentobarbital (EntobarVR, Hanlim Pharm Co. Ltd., Seoul, Korea) at a dose of 150 $\mathrm{mg} / \mathrm{kg}$ body weight. The animals in the control group were sacrificed first and all the dissection instruments thoroughly washed with $70 \%$ ethyl alcohol between dissections. After incising the abdominal aorta, the thorax was opened by cutting up through the diaphragm and ribs. Once the lungs were isolated, the lung lobes were carefully separated and each lobe weighed and stored at $-25^{\circ} \mathrm{C}$ in a $25 \mathrm{~mL}$ conical tube. The wet weight of each lung lobe is presented in Table 2 (exposure for 1 day) and Table 3 (exposure for 5 days). The lung burden of AuNPs was determined from the lung content of gold analyzed using ICP-MS (PerkinElmer NEXION 300S, Concord, ON, Canada) based on the National Institute for Occupational Safety and Health (NIOSH) 7300 method [13]. The lung lobes were digested with $2 \mathrm{ml}$ of concentrated nitric acid (purity of 69.0\%; CAS.no of 7697-37-2, Fluka, Germany) using a microwave digestion system (MARS 230/60, CEM, Matthews, NC). Thereafter, the concentrations of gold in the digested solutions were analyzed using ICP-MS and calculated using a calibration curve prepared with standard gold solutions $(0$, $0.05,0,2,0,5$ and $2 \mathrm{ppb})$. The spiked standard curve $(0$, $1,2,5$, and $20 \mathrm{ng} / \mathrm{g}$ ) and gold recovered from tissue were analyzed using the gold nanoparticles collected from the inhalation chamber and fresh lung tissue (non-exposed). The spiked standard curve for $0,1,2,5$, and $20 \mathrm{ng} / \mathrm{g}$ was analyzed as $0.24,0.93,1.98,5.33$, and $17.45 \mathrm{ng} / \mathrm{g}$, respectively. The standard curve and $\mathrm{R}^{2}$ were $\mathrm{y}=$ $0.8612 x+0.1229$ and 0.9972 of $R^{2}$, respectively. The recoveries were $93.24 \%$ for $1 \mathrm{ng} / \mathrm{g}, 99.12 \%$ for $2 \mathrm{ng} / \mathrm{g}$, $106.54 \%$ for $5 \mathrm{ng} / \mathrm{g}$, and $87.24 \%$ for $20 \mathrm{ng} / \mathrm{g}$. The limit of detection (LOD) and the limit of quantification (LOQ) were $13.61 \mathrm{ng} / \mathrm{g}$ and $41.23 \mathrm{ng} / \mathrm{g}$, respectively. When analyzing the ICP-MS, the control samples included 10 dilutions using $0.1 \mathrm{HNO}_{3}$, while the exposure samples included 1000 dilutions. The background gold for the digestion procedure was also validated using the same procedure with nitric acid only, where the background intensity was similar to the blank solution, $0.1 \%$ nitric acid. The recovery yields of AuNPs were 87.2-106.5\%, as shown in Fig. 1. The digestion recovery of AuNPs from the lung tissue was calculated using Eq. 1

$$
\begin{aligned}
& \text { Recovery }(\%) \\
& \quad=\text { measured concentration }(\mathrm{ng} / \mathrm{g}) / \text { spiked concentration }(\mathrm{ng} / \mathrm{g}) \times 100
\end{aligned}
$$

\section{Statistical analysis}

An analysis of variance (ANOVA) test and Dunnett T3 multiple comparison tests were used to compare the 

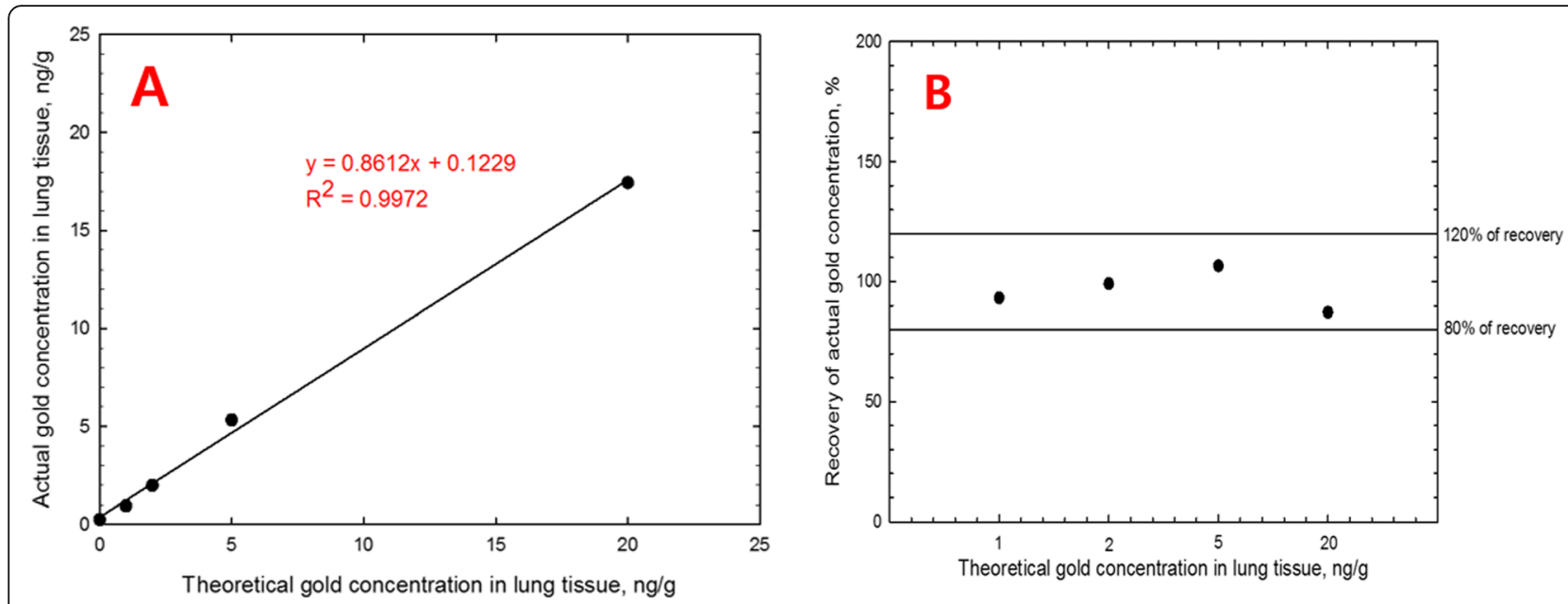

Fig. 1 Results of spiked standard curve and recovery for AuNPs; a, spiked standard curve for gold nanoparticles (ng/g) in lung tissue. Analysis was $y=0.8612 x+0.1229$ and $R^{2}=0.9972 ; \mathbf{b}$, Recovery results for gold nanoparticles in lung tissue. Recovery analysis for $1,2,5$, and $20 \mathrm{ng} / \mathrm{g}$ was 93.24 , $99.12,106.54$, and $87.24 \%$, respectively

gold content among the different lobes. The level of significance was set at $P<0.05$.

\section{Results}

\section{AuNP distribution and mass concentration}

The AuNP aerosol total number concentration, CMD (count median diameter), GSD (geometric standard deviation), and surface area measured and calculated by the DMAS are all presented in Table 1.

The mass concentration estimated by the DMAS was $47.21 \pm 3.33 \mu \mathrm{g} / \mathrm{m}^{3}$, while the mass concentration analyzed by the AAS after filter sampling was $34.7 \pm 2.8 \mu \mathrm{g} / \mathrm{m}^{3}$ (Table 1). The AuNPs observed by TEM were spherical in

Table 1 Distribution of AuNPs in inhalation chamber (mean \pm SD)

\begin{tabular}{|c|c|}
\hline AuNPs & Mean \pm SD \\
\hline 1-day exposure number $\left(\# / \mathrm{cm}^{3}\right)^{a}$ & $1.671 \times 10^{6} \pm 9.094 \times 10^{4}$ \\
\hline 5-day exposure number $\left(\# / \mathrm{cm}^{3}\right)^{a}$ & $1.823 \times 10^{6} \pm 8.805 \times 10^{4}$ \\
\hline $\mathrm{CMD}(\mathrm{nm}), \mathrm{GSD}^{\mathrm{a}}$ & $10.871,1.426$ \\
\hline Surface area $\left(\mathrm{nm}^{2} / \mathrm{cm}^{3}\right)^{a}$ & $8.972 \times 10^{8} \pm 4.742 \times 10^{7}$ \\
\hline Volume $\left(\mathrm{nm}^{3} / \mathrm{cm}^{3}\right)^{\text {a }}$ & $2.445 \times 10^{9} \pm 1.725 \times 10^{8}$ \\
\hline One particle mass (ng) ${ }^{a}$ & $2.590 \times 10^{-8} \pm 1.272 \times 10^{-9}$ \\
\hline Mass concentration $\left(\mathrm{ug} / \mathrm{m}^{3}\right)^{a}$ & $47.212 \pm 3.331$ \\
\hline $\mathrm{CMD}^{\mathrm{b}}(\mathrm{nm})$ and GSD & $11.21,1.43$ \\
\hline $\begin{array}{l}\text { AuNP mass concentration by } \\
\text { AAS }\left(\mu \mathrm{g} / \mathrm{m}^{3}\right)^{\mathrm{C}}\end{array}$ & $\begin{array}{l}\text { 1-day exposure, } 34.827 \pm 3.635 \\
\text { 5-day exposure, } 34.679 \pm 2.587\end{array}$ \\
\hline \multicolumn{2}{|c|}{$\begin{array}{l}\text { a Particle concentration and distribution were measured by DMAS; } \mathbf{b} \text { CMD was } \\
\text { measured by FE-TEM counting } 200 \text { particles and GSD was calculated by size of } \\
84 \% \text { / 50\%; c AuNP mass concentration was analyzed by AAS; CMD, count } \\
\text { median diameter; GSD, Geometric standard deviation; AAS, atomic absorption } \\
\text { spectrometer; SMPS continually measured during } 5 \text {-day exposure; } 3 \text { MCE filter } \\
\text { samples per day were collected during exposure period and measured to } \\
\text { determine mass concentration }\end{array}$} \\
\hline
\end{tabular}

shape and non-aggregated/agglomerated with CMD 11.21 nm and CMD 1.43 (Figs. 2 \& 3, Table 1). The CMD and GSD were 10.87 and 1.59, respectively, and Fig. 4 shows the particle diameter, surface area, and volume distribution of the generated AuNPs in the exposure chamber during the 5-day exposure period.

\section{AuNP deposition/retention in lung lobes after 1-day (6-h) exposure}

The AuNP deposition/retention per lobe is shown in Table 2, where the RCr (right cranial lobe), RM (right middle lobe), RCa (right caudal lobe), RA (right accessory lobe), and LL (left lung) retained 9.2, 14.4, 28.5, 12.0, 13.5, and $36.1 \%$ of the total lung deposition/retention, respectively; however, taken into account the different weights of the lung lobes, the AuNPs were evenly deposited/retained in terms of $\mu \mathrm{g} / \mathrm{g}$ of lung tissue. (Table 2). The gold nanoparticle retention in the lung lobes after the 5-day exposure showed a similar retention pattern to that after the 1day (6-h) exposure, with no statistically significant difference among the lobar concentration per unit weight. The retention percentages per lobe were also very similar after the 1-day and 5-day exposure periods. Finally, when comparing the deposition/retention for the 1-day exposure with the retention for the 5-day exposure, no notable clearance of AuNPs was observed in terms of the total lung deposition for the 5-day exposure period.

\section{AuNP deposition/retention in lung lobes after 5-day exposure}

The retention trend for the 5-day exposure was very similar to that for the 1-day (6-h) exposure (Table 3), with no statistically significant difference in AuNP retention among the lobes. Plus, the retention percentages 

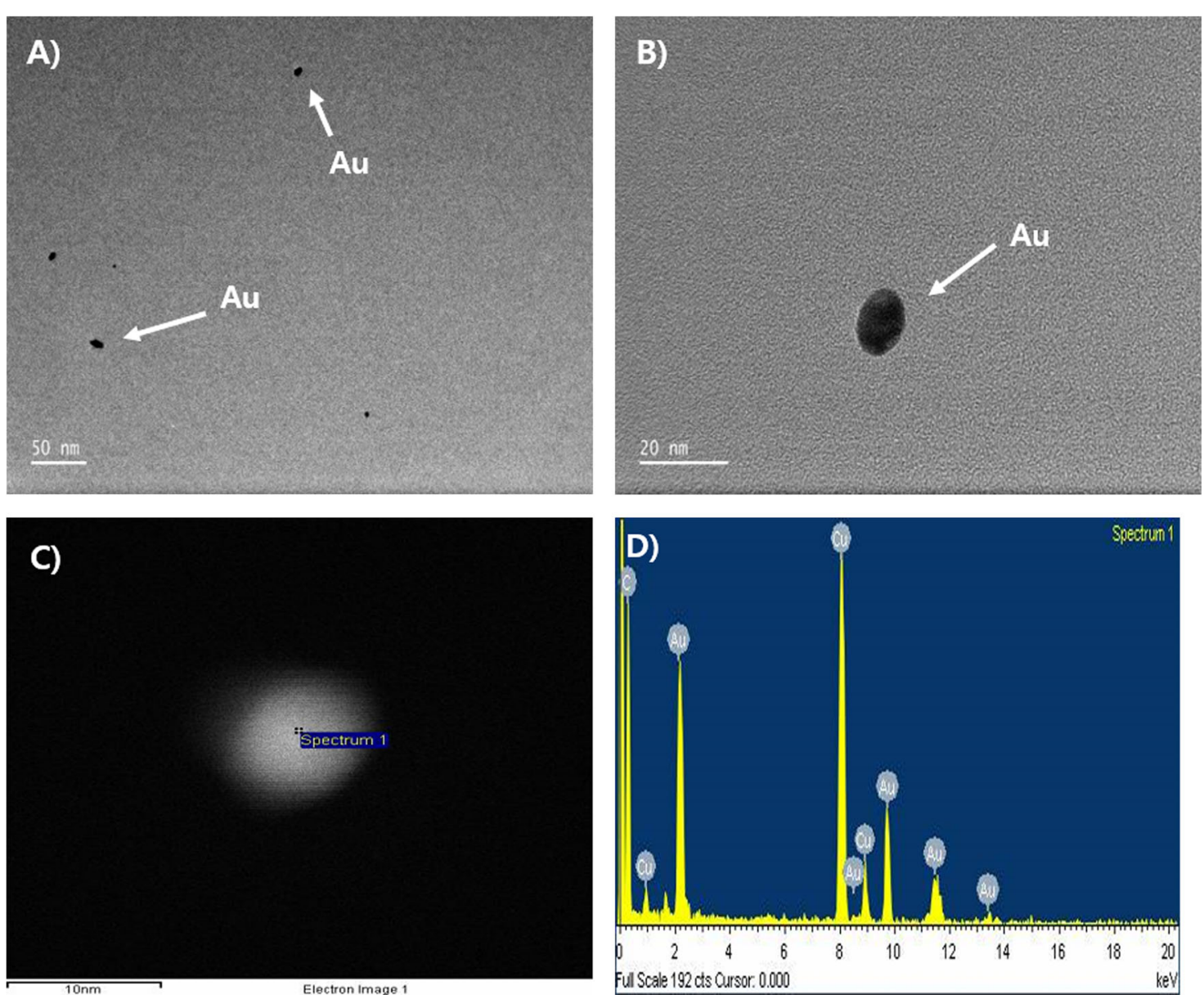

Fig. 2 TEM of AuNPs sampled from nose-only chamber. a, Non-aggregated/agglomerated AuNPs (scale 50 nm); b, AuNP (scale20 nm); c, EDX analysis of particle (scale $50 \mathrm{~nm}$ ), marked as 'spectrum 1'; d, EDX results indicate approximately $100 \%$ gold
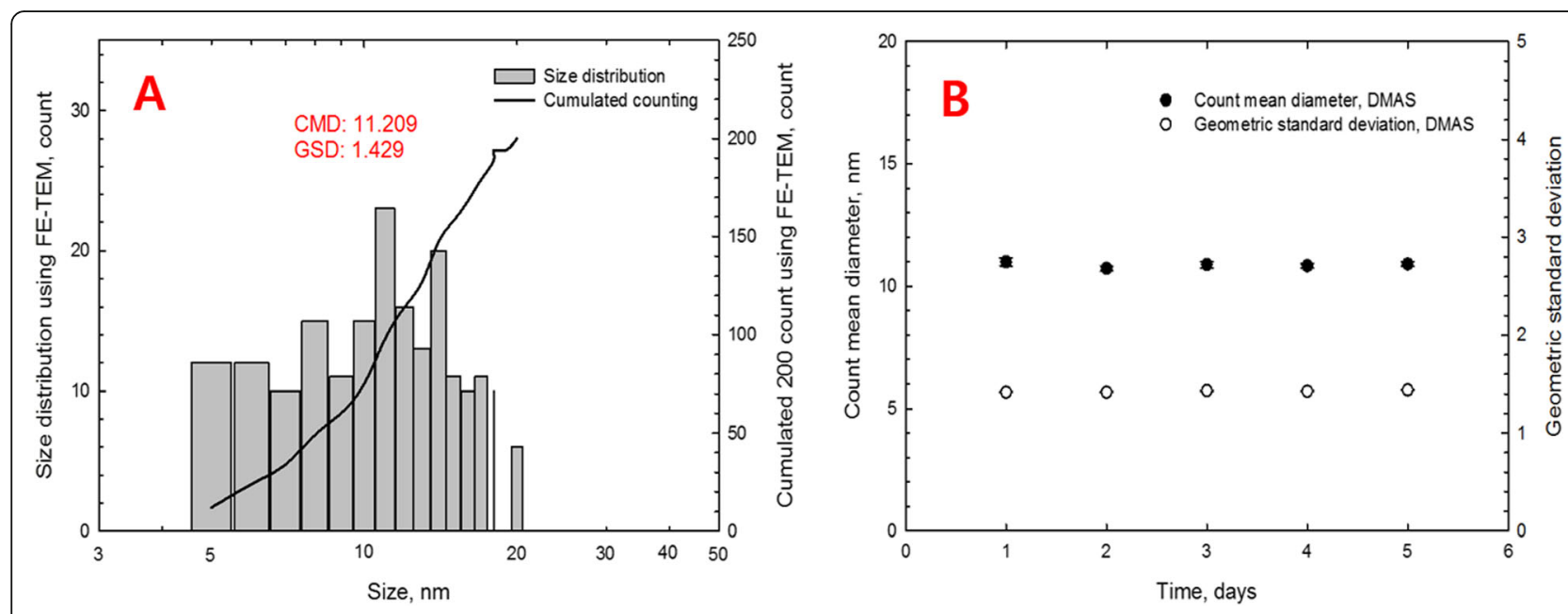

Fig. 3 Size distribution of AUNPs by TEM counting and DMAS. Count median diameter (CMD), geometric standard deviation (GSD). b, particle CMD and GSD were measured by DMAS during $6 \mathrm{~h} /$ day over 5-day exposure period 


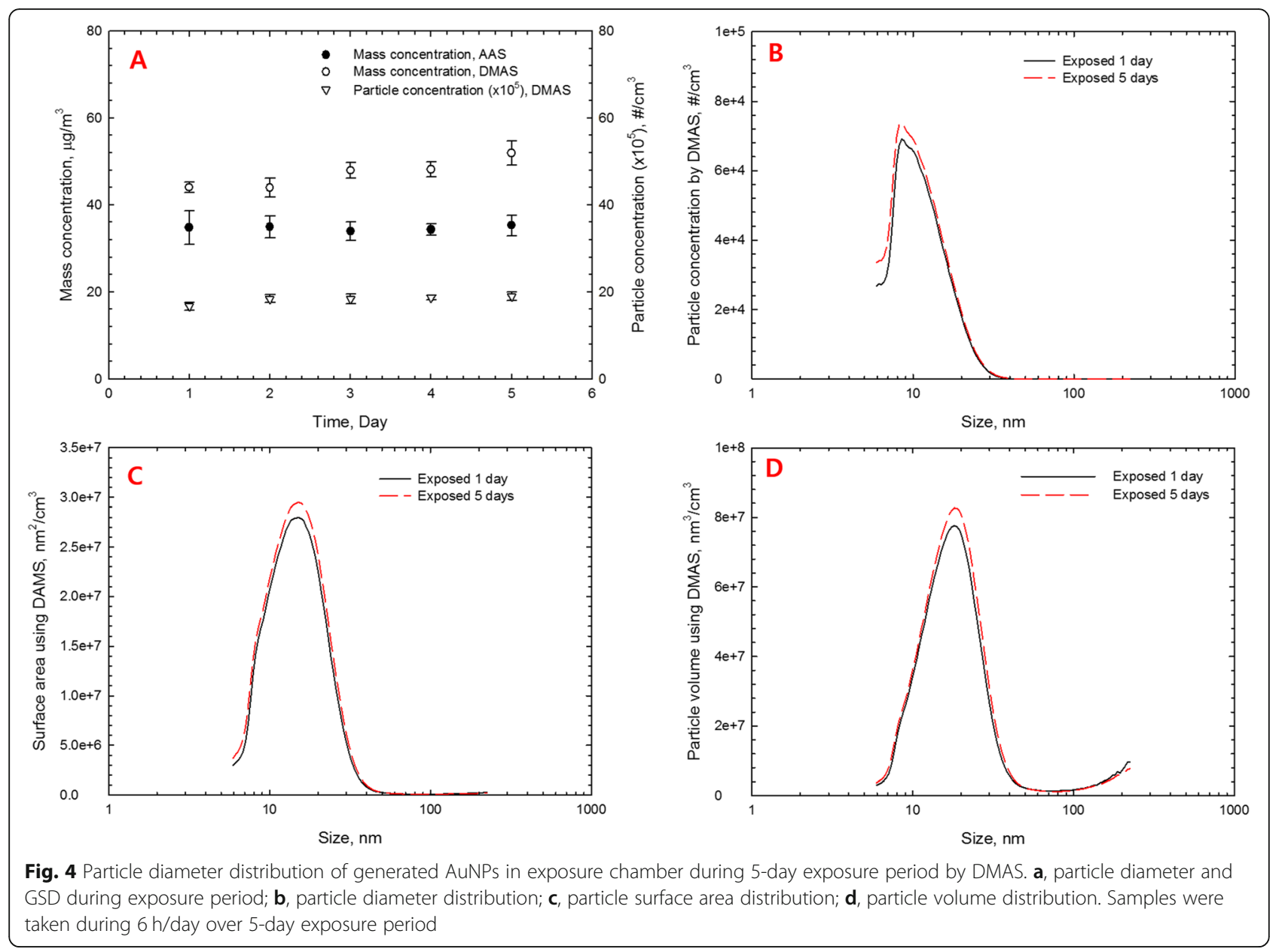

per lobe after the 5-day exposure were very similar to those after the 1-day exposure with no statistically significant difference. No significant clearance of AuNPs from the lung lobes was observed during the 5-day exposure, as the retention remained similar to that after

Table 2 Gold concentration in each lung lobe after 1-day exposure

\begin{tabular}{llll}
\hline Lobes & Retention $(\boldsymbol{\mu g} / \mathbf{g})^{\mathbf{a}}$ & Lung weight $^{(\mathbf{g})^{\mathbf{b}}}$ & $\begin{array}{l}\text { Retention }^{\mathbf{c}} \\
(\boldsymbol{\mu} \mathbf{g}) / \mathbf{l o b e}^{\mathbf{c}}\end{array}$ \\
\hline $\mathrm{RCr}$ & $2.61 \pm 0.62$ & $0.11 \pm 0.02$ & $0.30 \pm 0.08(9.15 \%)$ \\
$\mathrm{RM}$ & $3.36 \pm 0.85$ & $0.14 \pm 0.02$ & $0.47 \pm 0.16(14.42 \%)$ \\
$\mathrm{RCa}$ & $2.85 \pm 0.70$ & $0.32 \pm 0.02$ & $0.92 \pm 0.23(28.42 \%)$ \\
$\mathrm{RA}$ & $3.21 \pm 0.59$ & $0.12 \pm 0.01$ & $0.39 \pm 0.10(11.99 \%)$ \\
$\mathrm{RL}$ & $2.98 \pm 0.65$ & $0.69 \pm 0.05$ & $2.07 \pm 0.51(63.98 \%)$ \\
$\mathrm{LL}$ & $2.86 \pm 0.68$ & $0.41 \pm 0.04$ & $1.17 \pm 0.29(36.02 \%)$ \\
Total lung & $2.94 \pm 0.64$ & $1.10 \pm 0.09$ & $3.24 \pm 0.78$ \\
\hline
\end{tabular}

(mean \pm S.D); 5 animals; No significant change for all contents; RCr, right cranial; RM, right median; $\mathrm{RCa}$, right caudal; $\mathrm{RA}$, right accessory lobe; $\mathrm{RL}$, whole right lung $(\mathrm{RCr}+$

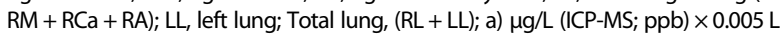
(end of volume) / lobe weight = gold concentration in $1 \mathrm{~g}$; b) Each lobe weight; c) Retained mass concentration $\mathrm{x}$ lung lobe weight = gold concentration in lobe; the 1-day exposure (Table 3). Our previous study on clearance of AuNP after 5-day inhalation exposure showed that AuNPs were located in the alveolar region and macrophages throughout the 28-day recovery period (Supplement 1).

Table 3 Gold concentration in each lung lobe after 5-day exposure

\begin{tabular}{|c|c|c|c|}
\hline Lobes & Retention $(\mu \mathrm{g} / \mathrm{g})^{\mathrm{a}}$ & Lung weight $(g)^{b}$ & $\begin{array}{l}\text { Retention } \\
(\mu \mathrm{g}) / \text { lobe }^{c}\end{array}$ \\
\hline $\mathrm{RCr}$ & $11.13 \pm 2.44$ & $0.11 \pm 0.01$ & $1.23 \pm 0.21(7.85 \%)$ \\
\hline RM & $15.64 \pm 2.45$ & $0.14 \pm 0.01$ & $2.17 \pm 0.38(13.86 \%)$ \\
\hline $\mathrm{RCa}$ & $14.85 \pm 1.98$ & $0.32 \pm 0.02$ & $4.70 \pm 0.49(30.06 \%)$ \\
\hline RA & $14.70 \pm 3.93$ & $0.13 \pm 0.02$ & $1.84 \pm 0.46(11.77 \%)$ \\
\hline $\mathrm{RL}$ & $14.39 \pm 2.12$ & $0.69 \pm 0.04$ & $9.93 \pm 0.96(63.54 \%)$ \\
\hline LL & $13.76 \pm 2.63$ & $0.42 \pm 0.04$ & $5.70 \pm 0.55(36.46 \%)$ \\
\hline Total lung & $14.12 \pm 2.03$ & $1.11 \pm 0.08$ & $15.63 \pm 1.33$ \\
\hline
\end{tabular}

(mean \pm S.D); 5 animals; * $P<0.05$; comparing $\mathrm{RCa}, \mathrm{RL}, \mathrm{LL}$, and total lung; $\mathrm{RCr}$, right cranial; $\mathrm{RM}$, right median; $\mathrm{RCa}$, right caudal; $\mathrm{RA}$, right accessory lobe; $R L$, whole right lung $(R C r+R M+R C a+R a) ; L L$, left lung; Total lung, $(\mathrm{RL}+\mathrm{LL}) ; \mathrm{a}) \mu \mathrm{g} / \mathrm{L}(\mathrm{ICP}-\mathrm{MS} ; \mathrm{ppb}) \times 0.005 \mathrm{~L}$ (end of volume) / lobe weight $=$ gold concentration in $1 \mathrm{~g}$; b) Each lobe weight; c) Retained mass concentration $\mathrm{x}$ lung lobe weight $=$ gold concentration in lobe; 


\section{Discussion}

The newly revised OECD inhalation toxicity guidelines mandate bronchoalveolar lavage and lung burden measurements if the inhaled particles or nanoparticles are poorly soluble and likely to be retained in the lungs. This revision requires a $2-3$-fold increase in the number of experimental animals used in order to collect sufficient information on the clearance kinetics, along with modifications to the inhalation toxicity equipment with more exposure ports for nose-only inhalation exposure and additional animal cages for whole-body exposure. The manual process involved in BAL fluid collection also means more labor-intensive experiments. As a result, all these additions incur extra financial costs. Therefore, in the case of nanomaterial inhalation, the current and previous papers by the present authors suggest halving the animal use and maximizing the endpoints by using one lobe of the right lung for the lung burden measurement. Demonstrating an even lobar deposition/retention of inhaled soluble silver nanoparticles in rat lungs implies extended application to poorly soluble or insoluble nanoparticles. Meanwhile, the mass concentration of AuNPs in each lung lobe also showed an even deposition, with no statistically significant difference in AuNP deposition after 6-h exposure or 5-day exposure in terms of gold mass/g of lung tissue. Another study also showed no statistically significant difference in soluble AgNP deposition among lobes after 6-h or 5-day exposure [3]. The only significant difference between AgNP and AuNP deposition/retention was AuNPs showed no significant clearance, whereas AgNPs showed approximately $30 \%$ clearance during the 5-day exposure period.

Several studies on the pulmonary deposition of $0.2-$ $3.05 \mu \mathrm{m}$ particles, including mono-dispersed (MMAD $1.5 \mu \mathrm{m}$ ) and poly-dispersed (MMAD $1.9 \mu \mathrm{m})$, found that the apical lobe of the right lung $(\mathrm{RCr})$ received the highest deposition $[14,15]$. Another particle deposition study using hamsters labeled with 99mTC $(0.01-3.0 \mu \mathrm{m} ; 10 \%$ $\leq 0.1 \mu \mathrm{m} ; 70 \% 0.1-0.4 \mu \mathrm{m}$, and $4 \% \geq 1.0 \mu \mathrm{m})$ resulted in a more even distribution with preferential deposition in the apical lobes [16]. When the particle deposition fractions in the nasal passages and in various lobes and regions of Long-Evans rat lungs were measured following nose-only exposure to $59 \mathrm{Fe}$ radiolabeled monodispersed condensation particles of triphenylphosphate, ranging from $0.9-4.2 \mu \mathrm{m}$, the left lung received a higher deposition than each lobe in the right lung. In the right lung, the caudal and accessory lobes showed the highest and lowest deposition, respectively, while the right medial and right cranial lobes showed similar depositions [17]. However, the main differences between the AgNP and AuNP studies by the current authors and other previous studies are the particle size and associated deposition mechanisms. The present study used a well-dispersed
$11 \mathrm{~nm}$ AuNP aerosol that was deposited in the respiratory tract almost exclusively by diffusion, while other studies have used submicron to micron size particles with different deposition mechanisms, such as impaction and sedimentation. Therefore, the diffusion-dominant deposition mechanism of nanoparticles produced an even particle deposition among the lung lobes, representing a significant difference between nano-sized and micron-sized aerosols as regards even lung deposition.

Recent study by the current authors on the lung deposition and retention of multi-walled carbon nanotubes (MWCNTs) (MMAD $1.015 \mu \mathrm{m}$ ) after 28 days of inhalation and during 28 days post exposure showed that the lung clearance kinetics of MWCNTs could be effectively evaluated using one lobe from the right lung [18]. The BAL fluid was collected from the right lung after occluding the right caudal lobe (RCL) and left lung. The left lung was then used to evaluate the histopathology and the RCL to evaluate the lung burden [18]. As a result, the number of animals used was greatly reduced. Although the evenness of lobar deposition was not evaluated in that study, the results still suggested that the lung clearance kinetics could be effectively evaluated using a right lung lobe or consistently using the same lobe in the right lung. In another recent study, quantitative analyses of lung burdens on various shapes of carbon nanomaterials including carbon black $\left(50 \mathrm{mg} / \mathrm{m}^{3}\right)$, NM-401 $\left(0.5\right.$ and $\left.1.5 \mathrm{mg} / \mathrm{m}^{3}\right)$, NM-403 $\left(1.5 \mathrm{mg} / \mathrm{m}^{3}\right)$ and MWCNT-7 $\left(1.5 \mathrm{mg} / \mathrm{m}^{3}\right)$ nanotubes were conducted after 28-day inhalation exposure. Their MMAD was $940 \mathrm{~nm}$ for printex-90 carbon black, $790 \mathrm{~nm}$ for NM-401, $1940 \mathrm{~nm}$ for NM-403, and $1780 \mathrm{~nm}$ for MWCNT. The median right lobe was separated and used for lung burden analysis successfully [19]. Therefore, the 3R principles (Reducing, Replacing, and Refining) may also be applied to fibrous MWCNTs, along with soluble AgNPs and insoluble AuNPs.

There is a concern whether the exposure duration used in this study, such as 5-day short-term exposure can simulate the standard of OECD inhalation toxicity subacute and subchronic tests and represent the subacute and subchronic exposure setting. Although there is no study on even lobar retention study after subacute and subchronic inhalation for nanomaterials, AuNP toxicokinetic study after acute exposure by Krelyling et al. [20] or short-term exposure (5-day) [12] or subacute exposure (28-day) conducted by our group (manuscript in revision) indicated that AuNP is insoluble, and has long elimination halftime, and eliminated very slowly with linear fashion. Elimination half-time of AuNP is $\left(\mathrm{T}_{1 / 2}\right) 45$ days [12] and our recent study AuNP 28-day exposure study indicated that elimination half-time is $\left(\mathrm{T}_{1 / 2}\right) 81.5$ days and elimination rate $0.0085 /$ day (manuscript in submission). Therefore, the deposition and elimination of AuNP in 28-day exposure may be predictive with 5-day exposure. Therefore, similar deposition and lung burden pattern after subacute 
exposure would be expected as seen in a 5-day exposure study. Furthermore, silver nanoparticle (AgNP) subacute study conducted together with lung burden measurement according to the revised OECD test guideline 412 showed Ag clearance had two-phase clearance; fast and slow. The fast clearance, half-time ranging from 2 to 4 days, was the clearance for soluble Ag and the slow clearance, half-time ranging from 57 to 100 days, was the clearance of the insoluble secondary AgNP generated from reacting the soluble Ag with biogenic molecules. The insoluble secondary AgNP had long half-time of elimination and eliminated very slowly with linear fashion [21]. Therefore, if similar deposition and clearance were expected for certain soluble and insoluble nanomaterials, lung burden or retention after short-term exposure could be extrapolated to subacute and subchronic exposure situations.

It should also be noted that the current findings of even nanoparticle deposition and retention in the lung lobes after inhalation were based on the useof $\sim 11 \mathrm{~nm}$ AuNPs, $\sim 20 \mathrm{~nm}$ AgNPs, and male Sprague-Dawley rats. Thus, caution is needed when using a single lung lobe to measure the lung burden and clearance following exposure to larger particles with impaction and sedimentation as the dominant deposition mechanisms. Moreover, longer-term inhalation studies with poorly soluble NPs or soluble NPs are needed to determine the evenness of lobar retention under such conditions, as the clearance may differ for different lung lobes. As such, the present findings may be limited to the particle size distribution, test material, and strain of animals used in this study. Despite these limitations, continuous efforts on reducing animals should be practiced.

\section{Conclusions}

This study evaluated the evenness of deposition/retention of insoluble gold nanoparticles in rat lung lobes to confirm whether the results would follow the previously reported evenness of deposition/retention of soluble silver nanoparticles. The current results showed that 11 nm inhaled well-dispersed AuNPs were evenly deposited and retained in all lung lobes in terms of the Au mass per gram of lung tissue after 1 day and 5 days. Thus, the consistently even deposition and short-term retention of inhaled AuNPs per unit weight of rat lung lobe agreed well with the previous study using soluble Ag nanoparticles, indicating that any lung lobe can be used to predict the total lung burden, as long as the same lobe is sampled for the same measurement. This allows the remaining lung lobes to be used for BALF and histopathological analyses, provided proper occlusion of the lung lobe is performed for the lung burden measurement. Consequently, combining the lung burden measurement, histopathological tissue preparation, and BALF assay from one rat can minimize the number of animals used and maximize the number of endpoints measured.

\section{Supplementary information}

Supplementary information accompanies this paper at https://doi.org/10. 1186/s12989-020-00384-w.

Additional file 1 Supplement 1. Hyperspectral microscopic images of gold nanoparticles (13 nm and $105 \mathrm{~nm}$ ) after 5-day inhalation exposure and post-exposure observations ( 3 and 28 day). Adopted from Fig. 10 of Han et al. (2015). Fig. 10. Small a and large b gold nanoparticles in rat lung sections observed by hyperspectral microscopy. Arrows indicate gold nanoparticles accumulated in multiple areas of lungs, including alveolar region and alveolar macrophages. a 28 days after small gold nanoparticle exposure; b 28 days after large gold nanoparticle exposure.

\section{Acknowledgements}

Not applicable

\section{Authors' contributions}

HPK, experimental and manuscript preparation; JKK, experimental preparation and manuscript preparation; MSJ, experimental preparation; JDP, experimental preparation and manuscript preparation; KA, nanomaterial generation and aerosol monitoring advice; MG, advice and manuscript review; GO, experimental planning, manuscript preparation and review; IJY, experimental planning, manuscript preparation and review. All authors read and approved the final manuscript.

\section{Funding}

This study was supported by the Global Top Environment Technology Development project (No. 2018001860004) funded by the Korean Ministry of Environment and 3-Dimensional Real-Time Measurement of Particulate Matters Near Sources using a Drone System project (No. 2019M1A2A210400212) by the National Research Foundation of Korea.

Availability of data and materials

All data and materials are included in the manuscript, Tables and Figures.

Ethics approval and consent to participate

The rat experiments were approved by the Hanyang University Institutional Animal Care and Use Committee in South Korea (HY-IACUC-2019-0049).

\section{Consent for publication}

Not applicable.

\section{Competing interests}

The authors report no conflicts of interest. The authors alone are responsible for the content and writing of this article.

\section{Author details}

${ }^{1}$ Aerosol Toxicology Research Center, HCTm CO.,LTD, Icheon, South Korea. ${ }^{2}$ Department of Mechanical Engineering, Hanyang University, Ansan, South Korea. ${ }^{3}$ Deparment of Preventive Medicine, College of Medicine, Chung-Ang University, Seoul, South Korea. ${ }^{4}$ National Institute for Occupational Health, Johannesburg, South Africa. ${ }^{5}$ Haematology and Molecular Medicine, University of the Witwatersrand, Johannesburg, South Africa. ${ }^{6}$ Water Research Group, Unit for Environmental Sciences and Management, North West University, Private Bag X6001, Potchefstroom 2520, South Africa. ${ }^{7}$ Department of Environmental Medicine, University of Rochester, Rochester, NY, USA. ${ }^{8} \mathrm{HCT}$ CO.,LTD, Seoicheon-ro 578 beon-gil, Majang-myeon, Icheon 17383, South Korea.

Received: 14 June 2020 Accepted: 5 October 2020

Published online: 20 October 2020

\section{References}

1. OECD. (Organization Economic Cooperation and Development). OECD guideline for the testing of chemicals 412, 28-day (subacute) inhalation toxicity study. Paris: OECD; 2018.

2. OECD. (Organization Economic Cooperation and Development). OECD guideline for the testing of chemicals 413, 90-day (subchronic) inhalation toxicity study. Paris: OECD; 2018. 
3. Park JD, Kim JK, Kim YH, Jeon KS, Lee JH, Faustman EM, Lee HK, Ahn K, Gulumian M, Oberdorster G, Yu IJ. Lobar evenness of deposition/retention in rat lungs of inhaled silver nanoparticles: an approach for reducing animal use while maximizing endpoints. Part Fibre Toxicol. 2019;16:2.

4. RIVM (National Institute for Public Health and the Environment). Multiple Path Particle Dosimetry Model (MPPD v 1.0): A model for human and rat airway particle dosimetry. Bilthoven: RIVM Report 650010030; 2002.

5. Multiple-Path Particle Dosimetry Model (MPPD v. 3.04. 2018. nchial. Accessed 18 Jan 2018.

6. ICRP (International Commission on Radiological Protection). Human respiratory tract model for radiological protection. ICRP publication 66 . Ann ICRP. 1994;24(1-3):1-482.

7. Sung JH, Ji JH, Park JD, Yoon JU, Kim DS, Jeon KS, Song MY, Jeong J, Han BS, Han JH, Chung YH, Chang HK, Lee JH, Cho MH, Kelman BJ, Yu IJ. Subchronic inhalation toxicity of silver nanoparticles. Toxicol Sci. 2009;108: 452-61

8. Sung JH, Ji JH, Park JD, Song MY, Song KS, Ryu HR, Yoon JU, Jeon KS, Jeong J, Han BS, Chung YH, Chang HK, Lee JH, Kim DW, Kelman BJ, Yu IJ. Subchronic inhalation toxicity of gold nanoparticles. Part Fibre Toxicol. 2011; 8(1):16.

9. ISO/TR 19601. Nanotechnologies-aerosol generation for air exposure studies of nano-objects and their aggregates and agglomerates (NOAA). Geneva: ISO; 2017.

10. Ji JH, Jung JH, Yu IJ, Kim SS. Long-term stability characteristics of metal nanoparticle generator using small ceramic heater for inhalation toxicity studies. Inhal Toxicol. 2007;19:745-51.

11. Pauluhn J, Thiel A. A simple approach to validation of directed-flow noseonly inhalation chambers. J Appl Toxicol. 2007;27:160-7.

12. Han SG, Lee JS, Ahn K, Kim YS, Kim JK, Lee JH, Shin JH, Jeon KS, Cho WS, Song NW, Gulumian M, Shin BS, Yu IJ. Size-dependent clearance of gold nanoparticles from lungs of Sprague-Dawley rats after short-term inhalation exposure. Arch Toxicol. 2015;89(7):1083-94.

13. NIOSH (National Institute for Occupational Safety and Health). NIOSH manual of analytical method. Cincinnati: Elements by ICP (Nitric/perchloric acid ashing). NIOSH; 2003. p. 7300.

14. Raabe OG, Yeh H-C, Newton GJ, Phalen RF, Velasquez DJ. Deposition of inhaled monodisperse aerosols in small rodents. In: Walton WH, editor. Inhaled particles IV. New York: Pergamon Press; 1977. p. 3-22.

15. Thomas RL, Raabe OG. Regional deposition of inhaled 137Cs-labeled monodisperse and polydisperse aluminosilicate aerosols in Syrian hamsters. Am Ind Hyg Assoc J. 1978;39:1009-18.

16. Brain JD, Knudson DE, Sorokin SP, Davis MA. Pulmonary distribution of particles given by intratracheal instillation or by aerosol inhalation. Environ Res. 1976;11:13-33.

17. Asgharian B, Kelly JT, Tewksbury EW. Respiratory deposition and inhalability of monodisperse aerosols in Long-Evans rats. Toxicol Sci. 2003;71:104-11.

18. Kim JK, Jo MS, Kim Y, Kin TG, Shin JH, Kim BW, Kim HP, Lee HK, Kim HS, Ahn K, Oh SM, Cho WS, Yu IJ. 28-day inhalation study with evaluation of lung deposition and retention of tangled multi-walled carbon nanotubes. Nanotoxicology. 2020;14(2):250-62.

19. Devoy J, Nunge H, Bonfanti E, Seidel C, Gate L, Cosnier F. Quantitative measurement of carbon nanotubes in ra lung. Nanotoxicology. 2020. https://doi.org/10.1080/17435390.2020.1814439.

20. Kreyling WG, Möller W, Holzwarth U, Hirn S, Wenk A, Schleh C, Schäffler M, Haberl N, Gibson N, Schittny JC. Age-Dependent Rat Lung Deposition Patterns of Inhaled 20 Nanometer Gold Nanoparticles and their Quantitative Biokinetics in Adult Rats. ACS Nano. 2018;12:7771-90.

21. Jo MS, Kim JK, Kim Y, Kim HP, Kim HS, Ahn K, Lee JH, Faustman EM, Gulumian M, Kelman B, Yu IJ. Mode of silver clearance following 28-day inhalation exposure to silver nanoparticles determined from lung burden assessment including post-exposure observation periods. Arch Toxicol. 2020; 94(3):773-84.

\section{Publisher's Note}

Springer Nature remains neutral with regard to jurisdictional claims in published maps and institutional affiliations.

\section{Ready to submit your research? Choose BMC and benefit from:}

- fast, convenient online submission

- thorough peer review by experienced researchers in your field

- rapid publication on acceptance

- support for research data, including large and complex data types

- gold Open Access which fosters wider collaboration and increased citations

- maximum visibility for your research: over $100 \mathrm{M}$ website views per year

At BMC, research is always in progress.

Learn more biomedcentral.com/submissions 